\title{
CLASIFICACIÓN DE LAS ORACIONES DE RELATIVO: LÍMITES, SOLUGIONES Y NUEVA PROPUESTA
}

\section{THE CLASSIFICATION OF RELATIVE CLAUSES: LIMITS, SOLUTIONS AND A NEW PROPOSAL}

\author{
Esther Álvarez García \\ Universidad de León \\ esther.alvarez@unileon.es \\ orcid: 0000-0001-5020-099X
}

Resumen. Este artículo revisa las principales clasificaciones que se han realizado de las oraciones de relativo a lo largo de la gramática hispánica con el propósito de establecer posibles equivalencias entre ellas. Asimismo, se exponen los principales problemas que unas y otras propuestas presentan y que, generalmente, son consecuencia de incluir dentro de una clasificación de este tipo solamente aquellas oraciones prototípicas, con lo que se deja de lado un amplio abanico de estructuras encabezadas por un relativo. Por último, proponemos una clasificación propia de las oraciones de relativo con el objetivo de solventar los problemas previamente expuestos.

Palabras clave: oraciones de relativo; clasificación de oraciones; gramática del español; estructuras con relativo; historiografía lingüística.

Abstract. This paper reviews the principal way in which relative clauses have been classified in the Hispanic world with the purpose of establishing possible equivalences beetween them. Mention is also made of the principal problems the different proposals present and which are frequently a consequence of including only prototypical examples in any given classification and thereby leaving aside a wide variety of relative constructions. Finally, we propose our own classification of relative clauses with the aim of solving the problems previously presented.

Keywords: relative clauses; classification of relative clauses; Spanish grammar; relative constructions; linguistic historiography.

Recepción: 19 de agosto de 2019; aceptación: 20 de abril de 2020. 


\section{INTRODUCCIÓN*}

No cabe duda de que las oraciones de relativo han sido objeto de estudio de numerosos trabajos a lo largo de la historia de la gramática, probablemente por tratarse de estructuras muy rentables que permiten transmitir conceptos complejos, difíciles de comunicar, en ciertos casos, mediante otras construcciones. Así, cualquier hablante de español podría decir El alumno que estudie aprobará o, en su lugar, El alumno estudioso aprobará; sin embargo, resulta imposible encontrar una estructura alternativa que comunique la misma información que una oración de relativo en casos como el siguiente: El alumno que estudie todos los temas y asista a clase todos los días aprobará. Las oraciones de relativo se caracterizan, por tanto, por la productividad, pero también por la universalidad. Los estudios tipológicos muestran que las oraciones de relativo son estructuras comunes en las diversas lenguas conocidas hasta la fecha (Lehmann 1984; Grosu \& Landmann 1998; De Vries 2002), por lo que constituirían un universal lingüístico (Downing 1978).

Así pues, la cuestión inmediata que uno podría plantearse es qué define una oración de relativo. La respuesta a esta pregunta, sin embargo, no resulta tan inmediata, pues, pese a ser estructuras constantes en las lenguas, las oraciones de relativo no comparten las mismas características en todas ellas. Por ejemplo, en español se considera que las oraciones de relativo "se caracterizan por modificar a un segmento que les precede en el contexto sintáctico inmediato" (RAE y ASALE 2009, $\S 44.1 c)$. Sin embargo, en ciertas lenguas, dicho segmento puede aparecer pospuesto a la oración de relativo -es el caso de las lenguas prenominales como el chino mandarín o el vasco- o, incluso, en el interior de la propia oración relativa -como en las lenguas circunnominales (por ejemplo, el navajo o el tibetano). De manera semejante, no todas las oraciones de relativo desempeñan las mismas funciones semánticas, y éstas tampoco son comunes a todas las lenguas, por lo que una definición

* Para la realización de este trabajo, he contado con la ayuda designada a la Formación del Profesorado Universitario (FPU) del Ministerio de Educación, Cultura y Deporte del Gobierno de España, con número de referencia FPU13/06378. 
que parta exclusivamente de criterios de esta índole también resultaría problemática.

Ante esta situación, De Vries (2002) ofrece una definición de oración de relativo en la que aúna rasgos tanto sintácticos como semánticos. Así, una oración de relativo se caracteriza por a) ser un segmento subordinado y $b$ ) compartir con la oración principal un elemento al que denomina pívot. En una de las oraciones -principal o relativa ${ }^{1}$-, ese pívot se manifiesta por medio de una forma plena, y en la otra, mediante un relativizador que puede adoptar diferentes formas en función de la lengua: desde un pronombre personal hasta un pronombre relativo o, incluso, no tener una realización física -lo que se conoce como relativizador cero- (Moreno Cabrera 1991). Con tal definición de oración de relativo, De Vries busca explicar las múltiples formas que estas estructuras pueden adoptar en las diferentes lenguas naturales, incluido el español. Así, las oraciones relativas de este idioma están subordinadas a un segmento -destacado con cursivas en los ejemplos de (1)-, ya sea nominal ( $1 a)$ o de otro tipo $(1 b)$, de tal forma que su elisión da lugar a una estructura agramatical (1c) o inadecuada sin un contexto comunicativo específico $(1 d)$. Por lo demás, las oraciones principal y relativa comparten un elemento pívot, cuya forma plena aparece en la primera, mientras que el relativizador se manifiesta en la segunda (2). Por lo tanto, el español formaría parte del conjunto de lenguas que poseen relativas posnominales de núcleo externo (Moreno Cabrera 1991).

(1) a. El alumno [que estudie] aprobará.

b. [El que estudie] aprobará.

c. *Que estudie aprobará.

d. ?El que estudie.

(2) El alumno $\left[\right.$ que $_{\mathrm{i}}$ estudie] aprobará.

1 Según el tipo de lengua, la forma plena del elemento pívot aparece en la oración principal o en la relativa: en lenguas con relativas de núcleo externo, tanto prenominales como posnominales, dicho segmento aparece en la principal -y, por tanto, el relativizador en la oración relativa-, mientras que en lenguas con relativas de núcleo interno (es decir, circunnominales o correlativas), la forma plena del pívot aparece en la oración relativa -y, en consecuencia, el relativizador en la principal. 
Como veremos en los próximos apartados, la propuesta de De Vries (2002) se ajusta a las diferentes formas que una oración de relativo puede admitir en español. Es por ello por lo que esta definición será la que adoptemos en el presente trabajo.

Más allá de su definición, la mayoría de los autores reconoce que las diferencias entre las oraciones de relativo no sólo se manifiestan tipológicamente -es decir, cuando comparamos tipos de lenguas-, sino que estas estructuras también pueden presentar rasgos dispares dentro de una misma lengua, lo que ha suscitado el planteamiento de diversas clases de oraciones de relativo. Tal es, precisamente, el punto de partida de este artículo, cuyo propósito se centrará, en primer lugar, en hacer una revisión de las principales propuestas de clasificación de las oraciones de relativo. No adoptaremos una perspectiva tipológica, lo que llevaría a exceder los límites de este trabajo, sino que tomaremos como base el español y las gramáticas escritas sobre esta lengua. A partir de las clasificaciones, intentaremos analizar los problemas que éstas suscitan y que, con bastante frecuencia, son el resultado de analizar como oraciones de relativo solamente aquellas estructuras prototípicas -por ejemplo, (1a)-, ejercicio que deja de lado un amplio abanico de construcciones que constituyen, igualmente, oraciones de relativo ${ }^{2}$. Con todo ello, el objetivo último de nuestro trabajo será proponer una clasificación de las oraciones de relativo que, si bien comparte ciertos conceptos con propuestas clásicas, busca dar solución a las limitaciones que presentan.

\section{Clasificaciones PREVIAS de las ORAGIONES DE RElativo}

A la hora de llevar a cabo una clasificación (de las oraciones de relativo o de cualquier otra estructura) es fundamental establecer una serie de criterios claros y sistemáticos que justifique dicha clasificación. En el caso particular de las oraciones de relativo, se han empleado tanto criterios semánticos como sintácticos, aunque los primeros parecen haber tenido un mayor peso en la tradición gramatical en lengua española. Ello no es

${ }^{2}$ Intentaremos ofrecer ejemplos de los diferentes tipos de oraciones de relativo a partir de muestras de habla real. Concretamente, estos ejemplos se han tomado de los corpus académicos CREA y CORPES XXI, según criterios de selección que toman en cuenta una misma diacronía (2000-2009) y una misma distribución geográfica (español europeo). 
de extrañar si tenemos en cuenta que, tal y como señala Coseriu (1977, p. 38), "en el lenguaje el significado, y no la expresión, es lo determinante", y que, por tanto, "la expresión existe por el significado, no a la inversa". Por consiguiente, en este apartado repasaremos diversas clasificaciones de las oraciones de relativo en español atendiendo, en primer lugar, a criterios semánticos; en segundo, a criterios sintácticos; y, por último, a una combinación de ambos.

\section{Criterios semánticos}

La primera clasificación de las oraciones de relativo fue establecida por la escuela francesa de Port-Royal en su Logique (véase Donzé 1970). Estos autores establecieron dos tipos de oraciones relativas: determinativas y explicativas. Para ello, emplearon como criterios clasificadores dos notas semánticas: a) la restricción del antecedente y $b$ ) la adición de una nueva predicación. Así, las relativas determinativas se definen como aquellas oraciones que restringen la extensión de su antecedente pero no añaden una nueva predicación, mientras que las relativas explicativas no restringen su antecedente y sí añaden una nueva predicación ${ }^{3}$. A partir de estos criterios, la oración relativa de (3a) sería determinativa, ya que restringe la extensión del antecedente los estudiantes. Se entiende, por tanto, que no todos los estudiantes se fueron de viaje, sino sólo aquellos que habían aprobado. Por el contrario, (3b) sería explicativa, puesto que no restringe la extensión de su antecedente, sino que añade una nueva predicación sobre él: todos los estudiantes aprobaron y todos se fueron de viaje:

(3) $a$. Los estudiantes que aprobaron se fueron de viaje.

$b$. Los estudiantes, que aprobaron, se fueron de viaje.

La clasificación bipartita establecida por la escuela de PortRoyal fue seguida de cerca por autores posteriores como Bello (1978 [1847]), quien también diferenció entre relativas especificativas -término más frecuente que el de determinativas-y expli-

${ }^{3}$ Como consecuencia de estas características semánticas, los estudiosos de Port-Royal establecen una diferencia formal entre las relativas determinativas y las explicativas, pues las segundas, a diferencia de las primeras, pueden combinarse con antecedentes que hagan referencia a un ente individual. 
cativas a partir de criterios semánticos. No obstante, el autor venezolano solamente empleó una de las notas semánticas de la escuela francesa -la restricción del antecedente- y la combinó con un criterio de índole formal: la pausa. Así, las relativas explicativas, como $(3 b)$, son aquellas oraciones que no restringen la extensión de su antecedente y aparecen enmarcadas entre pausas, lo que en la escritura se ve reflejado en el uso de las comas. Por su parte, las relativas especificativas sí restringen la extensión de su antecedente, pero carecen de pausas, tal y como se observa en $(3 a)$.

Los principales gramáticos españoles del siglo xx se apoyaron en los criterios establecidos por Bello (1978 [1847]) y defendieron, por tanto, una clasificación bipartita de las oraciones de relativo en especificativas y explicativas (Gili Gaya 1961; Marcos Marín 1980; Alcina y Blecua 1975; Alarcos 1994; Matte Bon 1995 [1992]; Porto Dapena 1997). Algunos autores añadieron a estos dos criterios un tercero que afectaría, igualmente, a la esfera semántica de la oración: por ejemplo, la Academia, en su Esbozo de una nueva gramática de la lengua española (1973, $\S 3.20 .2$ ), apunta que las relativas explicativas pueden ser elididas sin que ello afecte el sentido general de la oración principal; las relativas especificativas, sin embargo, no pueden ser elididas sin que la oración resultante pierda el sentido original o sea falsa (Gili Gaya 1961; Alarcos 1994). En el ejemplo que propone la Academia, la elisión de la relativa especificativa de $(4 a)$ daría lugar a $(4 b)$, oración falsa, pues no todas las casas son pequeñas:

(4) a. Todas las casas que hemos visto son pequeñas.

$b$. Todas las casas son pequeñas.

Ciertos gramáticos defienden también una clasificación semántica de las oraciones de relativo, pero emplean términos diferentes para denominarlas. Por ejemplo, D'Introno (1979 y 2001; también véase Ojea López 1992) estableció dos tipos de oraciones de relativo que nombró restrictivas y no restrictivas ${ }^{4}, \mathrm{y}$ apuntó que el principal rasgo discrepante entre unas y otras era de naturaleza semántica, pues las relativas no restrictivas "expre-

${ }^{4}$ No obstante, y como veremos en el subapartado "Combinación de criterios..." (cf. infra), D’Introno (1979, p. 214) definió su clasificación de las oraciones de relativo como tripartita, puesto que, dentro de las relativas restrictivas, diferenció entre atributivas y apositivas. 
san un determinado estado de cosas que afecta a todos los elementos a los cuales refiere el SN antecedente", mientras que las relativas restrictivas "expresan un determinado estado de cosas que afecta a solo una parte de los elementos a los cuales refiere el SN" (1979, p. 214). Pese a emplear una terminología diferente, D'Introno hace uso, de nuevo, del criterio de la restricción del antecedente para proponer su clasificación de las oraciones de relativo. No obstante, a este criterio añade una serie de rasgos fonológicos y sintácticos que derivaría de esa diferencia semántica y que permitiría distinguir, desde un punto de vista formal, las relativas restrictivas y no restrictivas: la formación de un grupo fónico con el antecedente, el determinante con el que se combina dicho antecedente, el modo indicativo/ subjuntivo del verbo de la oración relativa, etcétera.

De manera semejante, Luján (1980) postuló una clasificación bipartita de las oraciones de relativo en la que diferenció entre restrictivas y apositivas. Las primeras se caracterizarían por designar un subconjunto en el conjunto de individuos al que hace referencia el antecedente, en tanto que las segundas no modificarían el conjunto de individuos designado por dicho antecedente. De nuevo, el criterio que empleó Luján para diferenciar entre relativas restrictivas y apositivas es la restricción del antecedente, por lo que su propuesta de clasificación coincide con la planteada por D'Introno (1979) en restrictivas y no restrictivas y con la clasificación tradicional en especificativas y explicativas defendida por numerosos gramáticos del siglo xx (Gili Gaya 1961; Marcos Marín 1980; RAE 1973; Alcina y Blecua 1975; Alarcos 1994; Matte Bon 1995 [1992]; Porto Dapena 1997).

Más recientemente, RAE y ASALE (2009) han defendido una clasificación bipartita de las oraciones de relativo en especificativas y explicativas y señalado que "la diferencia fundamental entre ambas radica en que las primeras precisan la denotación del grupo nominal del que forman parte, mientras que las segundas agregan cierta información, externa a ese grupo, que la completa” (\$ 44.11). El criterio que, por tanto, emplean RAE y ASALE en esta clasificación sigue siendo de índole semántica, pero presenta una importante diferencia respecto de las propuestas anteriores: ya no se tiene en cuenta el hecho de que la oración relativa restrinja o no la extensión del antecedente, sino la posibilidad de precisar o identificar el referente del antecedente. Así, las relativas especificativas permiten identificar el referente al que alude el sintagma nominal 
formado por el antecedente y la propia oración de relativo; las relativas explicativas, en cambio, no identifican dicho referente, pues ya está definido antes de introducir la oración de relativo. En este sentido, y pese a emplear la misma terminología, la clasificación de las oraciones de relativo que proponen RAE y ASALE en su Nueva gramática de la lengua española (NGLE) no es equivalente a la defendida por gramáticos anteriores (Gili Gaya 1961; Marcos Marín 1980; RAE 1973; Alcina y Blecua 1975; Alarcos 1994; Matte Bon 1995 [1992]; Porto Dapena 1997). Asimismo, RAE y ASALE (2009, § 44.4-5) señalan que la diferencia semántica entre especificativas y explicativas se vería reflejada en una serie de características prosódicas y sintácticas que permitiría distinguirlas desde un punto de vista formal: la formación de un grupo fónico independiente, el ámbito de aplicación de los determinantes y cuantificadores, la presencia de nombres propios o pronombres como antecedente, etcétera.

\section{Criterios sintácticos}

Menos frecuentes son las clasificaciones que, dentro de la gramática hispánica, se han realizado de las oraciones de relativo a partir de criterios sintácticos y no semánticos. Una de las primeras propuestas fue la de Roca-Pons (1960), quien diferenció dos tipos de oraciones de relativo, atributivas y apositivas, tomando como criterio clasificador su función sintáctica. Así, las relativas atributivas desempeñarían la función de atributo, que, según este autor, consistiría en modificar a aquel segmento nominal que funciona como núcleo y con el que conforman un mismo sintagma. Las relativas apositivas, que evidentemente realizarían la función de aposición, no formarían unidad sintáctica con su antecedente y podrían ser conmutadas por una oración coordinada. Roca-Pons ejemplificó ambos tipos de oraciones relativas de la siguiente manera, en que $(5 a)$ se corresponde con una relativa atributiva y $(5 b)$ con una relativa apositiva:

(5) a. Los alumnos que estaban atentos entendieron la explicación.

$b$. Los alumnos, que estaban atentos, entendieron la explicación. 
Pese a intentar apoyarse solamente en criterios sintácticos, la clasificación que sugiere Roca-Pons (1960) de las oraciones de relativo se corresponde fielmente con la propuesta tradicional que diferencia entre especificativas y explicativas a partir de criterios semánticos -y, de hecho, el propio autor establece este paralelismo en su obra-, lo que refleja el gran peso que tal clasificación ha tenido en otros planteamientos.

Más interesante, quizá por no coincidir con la clasificación semántica en especificativas y explicativas, es la propuesta de Porto Dapena (1997), quien intentó evitar la combinación de criterios proponiendo dos clasificaciones diferentes de las oraciones de relativo: una que atiende exclusivamente a criterios semánticos, y otra, a criterios estrictamente sintácticos. Esta segunda propuesta llevó a Porto Dapena a diferenciar entre relativas integradas y no integradas en función del segmento del que dependiese la oración relativa. Así, las relativas integradas son aquellas que están subordinadas a un único constituyente de la oración principal, es decir, el segmento subordinante no es toda la oración principal, sino una sola parte de ésta. Tal situación se da en las tradicionalmente conocidas como relativas especificativas $(6 a)$, pero también en las explicativas $(6 b)$, pues en ambos casos el relativo menciona únicamente al antecedente -subrayado en (6)-, por lo que la oración relativa -en cursiva- estaría subordinada a dicho constituyente:

(6) a. Los coches que estaban mal aparcados fueron multados. b. Los coches, que estaban mal aparcados, fueron multados.

Las relativas no integradas, en cambio, son aquellas en las que el relativo hace referencia a toda la oración principal y no sólo a uno de sus constituyentes, por lo que el antecedente se define ahora como oracional o proposicional: "es la primera oración -la en un principio considerada como principal- la que de alguna manera, al estar representada por el relativo, pasa a ser un constituyente de la secundaria" (Porto Dapena 1997, pp. 22-23). Esta situación se corresponde con casos como (7), en los que el antecedente equivale a la oración principal, de tal forma que, ahora, la relación de subordinación se manifiesta en el ámbito oracional, es decir, entre segmentos que constituyen verdaderas oraciones:

(7) Malú se casó la semana pasada, lo que me alegra enormemente. 
Oraciones con "donde", "cuando" y "como". Cuestión que merece análisis aparte es la de las oraciones introducidas por las unidades donde, cuando y como. Hasta el momento, sólo hemos revisado ejemplos con el pronombre que; no obstante, el paradigma español de los relativos es más amplio e incluye hasta ocho unidades $^{5}$ : que, el cual, quien, cuyo, donde, cuando, como y cuanto (Brucart 1999; RAE y ASALE 2009). De todas ellas, aquellas unidades que han suscitado un mayor debate en las gramáticas hispánicas son donde, cuando y como, pues no hay acuerdo sobre su categoría gramatical y, por ende, sobre el tipo de oraciones que introducen. Pese a ello, los criterios empleados para clasificar las estructuras encabezadas por estas unidades han sido de índole sintáctica, lo que justifica su inclusión en este subapartado.

La RAE (1973) o Gili Gaya (1961), entre otros estudiosos, señalan que las oraciones introducidas por donde, cuando o como "modifican cualitativa o cuantitativamente a la principal" (Gili Gaya 1961, p. 311), por lo que su papel sintáctico sería equivalente al de un adverbio. Es por ello por lo que estos gramáticos defienden que las estructuras encabezadas por dichas unidades no constituyen oraciones de relativo, sino subordinadas adverbiales.

Marcos Marín (1980; Marcos Marín, Satorre Grau y Viejo Sánchez 1998) o Alarcos (1994) apuestan, sin embargo, por una postura menos radical y señalan que, en primer lugar, es necesario diferenciar los contextos en los que suelen aparecer don$d e$, cuando y como, unidades que pueden introducir oraciones precedidas por un antecedente nominal -destacado con cursivas en (8)- u oraciones que carecen de él (9):

${ }^{5}$ Ciertos autores incluyen un noveno relativo dentro de este paradigma, pues consideran que el artículo definido y el pronombre que conforman una única pieza léxica en aquellos contextos en los que el antecedente está expreso y una preposición precede al relativo: el ordenador con el que trabajo. Diferencian, así, el relativo simple que del relativo compuesto el que (BELLo 1978 [1847]; Marcos Marín, Satorre Grau y Viejo Sánchez 1998; RAE y ASALE 2009). Otros autores, sin embargo, defienden que la estructura el que está compuesta por dos unidades independientes que se combinan sintácticamente, como demuestra el hecho de que el artículo pueda ser elidido: el ordenador con que trabajo (Alarcos 1994). 
(8) a. Coloqué los libros en la estantería donde estaban.

b. El día cuando llegaron se había desatado una fuerte tormenta.

c. Resolvió el ejercicio de la forma como le había explicado el profesor.

(9) $a$. Coloqué los libros donde estaban.

$b$. Cuando llegaron se había desatado una fuerte tormenta.

c. Resolvió el ejercicio como le había explicado el profesor.

En el primer contexto, la oración encabezada por donde, cuando o como complementa a un sustantivo de la misma forma como lo haría el pronombre que si apareciese en su lugar (10). Por tanto, su función sintáctica sería equivalente a la de un adjetivo, de manera que puede hablarse, evidentemente, de oraciones subordinadas adjetivas o relativas:

(10) $a$. Coloqué los libros en la estantería en la que estaban.

$b$. El día en el que llegaron se había desatado una fuerte tormenta.

c. Resolvió el ejercicio de la forma en la que le había explicado el profesor.

Análisis diferente merecen, según estos autores, las oraciones en las que donde, cuando y como carecen de un antecedente (9), pues la función que ahora desempeñan es la de aditamento -o complemento circunstancial- y, por tanto, equivaldrían a un adverbio. Es por ello por lo que en este segundo contexto donde, cuando y como introducirían oraciones subordinadas adverbiales, y no así oraciones de relativo.

J.A. Martínez (1989) defiende una clasificación similar y señala que las oraciones de (8) y (10) no presentan diferencia sintáctica alguna, por lo que tanto unas como otras constituyen oraciones de relativo; en cambio, las oraciones de (9) conformarían subordinadas adverbiales. No obstante, y pese a situarlas entre las subordinadas adverbiales, J.A. Martínez apunta que las oraciones encabezadas por donde, cuando y como en contextos como (9) no equivalen a adverbios, sino a sustantivos, por lo que su categoría sintáctica sería la propia de estas unidades (Alarcos 1982 [1970]).

Por último, y siguiendo la estela marcada por autores como J.A. Martínez (1989), Brucart (1999) argumenta que las oraciones introducidas por donde, cuando y como en contextos como 
(9) pueden reemplazarse con un sustantivo, por lo que ostentarían la misma categoría sintáctica que éstos. A ello añade que no sólo los adverbios, sino también los sustantivos, pueden ejercer la función sintáctica de aditamento (11), lo cual excluiría la necesidad de establecer diferencias entre unas oraciones y otras: tanto las de (8) como las de (9) constituyen oraciones de relativo, con la diferencia de que las primeras pertenecen a la categoría adjetiva, mientras que las segundas, a la nominal. Concretamente, las oraciones relativas que carecen de un antecedente explícito y pertenecen a la categoría nominal reciben el nombre de relativas libres $^{6}$ (RAE y ASALE $2009 \$ 44.7$ ):

(11) Escribiré la carta esta semana.

\section{Combinación de criterios: las clasificaciones tripartitas}

En este último subapartado revisaremos aquellas clasificaciones que parten de una combinación de criterios semánticos y sintácticos, lo que, generalmente, ha llevado a sus autores a distinguir más de dos tipos de oraciones de relativo. Es cierto que varias de las propuestas revisadas en el subapartado "Criterios semánticos" (cf. supra) contemplan no sólo diferencias semánticas, sino también formales entre las relativas especificativas y explicativas (Bello 1978 [1847]; Gili Gaya 1961; Marcos Marín 1980; RAE 1973; Alcina y Blecua 1975; Alarcos 1994; Matte Bon 1995 [1992]; RAE y ASALE 2009). No obstante, aquellas clasificaciones difieren de las que presentaremos en este subapartado en que, para las primeras, las diferencias formales son consecuencia de la función semántica que unas y otras oraciones de relativo desempeñan, por lo que se sitúan en un segundo plano. En las clasificaciones tripartitas, por el contrario, se diferencian más de dos tipos o subtipos de oraciones de relativo y, para cada una de estas distinciones, se emplean o bien criterios semánticos o bien criterios sintácticos, sin necesidad de coincidencia entre ellos. Es importante aclarar que, aunque hablemos ahora de clasificaciones tripartitas, no todas ellas establecen tres tipos diferentes de oraciones de relativo con idéntica jerarquía, sino

${ }^{6}$ Las relativas libres conforman, junto con las relativas semilibres -por ejemplo, El que llegue tarde al examen suspenderá-, las denominadas relativas sin antecedente expreso (BRUCART 1999; RAE y ASALE 2009) o, según una terminología más "clásica", las relativas sustantivadas. 
que, en varios casos, estas oraciones conformarán subtipos dentro de una primera distinción bipartita.

Las clasificaciones tripartitas vienen motivadas por la inclusión en las oraciones de relativo de estructuras como (12), denominadas relativas apositivas. Como vimos líneas arriba, algunos autores emplean este término para hacer referencia a las que tradicionalmente han recibido el nombre de explicativas, es decir, aquellas que no restringen la extensión de su antecedente (Luján 1980) ${ }^{7}$. Sin embargo, en las clasificaciones tripartitas, el término relativa apositiva se reserva para aludir a otro tipo de estructuras -con cursivas en (12)- que se caracterizan por a) contener una oración de relativo sin un antecedente nominal expreso, $b$ ) aparecer en aposición con un sintagma nominal previo $^{8}$ y $c$ ) estar enmarcadas entre pausas:

(12) a. Los venezolanos, los que tienen dinero, viajan al extranjero.

b. Los estudiantes, los que han suspendido el examen, no irán de viaje.

D'Introno (1979 y 2001) fue uno de los primeros en definir su clasificación de las oraciones de relativo como tripartita, ya que, a su distinción de las relativas en restrictivas y no restrictivas, añadió una segunda: las relativas restrictivas se subdividirían, a su vez, en atributivas $(13 a)$ y apositivas $(13 b)^{9}$ :

(13) a. Los venezolanos que tienen dinero viajan al extranjero. $b$. Los venezolanos, los que tienen dinero, viajan al extranjero.

7 BRUCART (1999) apunta que esta terminología surge en la tradición anglosajona, en la que se considera que la relación entre el antecedente y la relativa explicativa es semejante a la que se establece entre dos segmentos en aposición. Aunque escapa al propósito del presente artículo, consideramos que no es correcta la identificación de las relativas explicativas con estructuras apositivas, pues estas oraciones no cumplen las características propias de aquellos segmentos que aparecen en aposición: a) ser intercambiables e independientes, $b$ ) poder introducir partículas explicativas entre dichos segmentos y $c$ ) poder establecer una relación de predicación entre ellos. Véanse J.A. Martínez 1994 y Suñer 1999.

8 A diferencia de las relativas explicativas, este tipo de estructuras sí cumplen las características definitorias de los segmentos en aposición mencionadas en la nota anterior.

9 En su obra de 2001, D’InTrono renombró las restrictivas apositivas como parentéticas, pero las diferencias que estableció entre éstas y las restrictivas atributivas siguen siendo las mismas. 
Mientras que el criterio que permitía distinguir entre relativas restrictivas y no restrictivas era semántico -la restricción del antecedente-, las diferencias entre las restrictivas atributivas y las apositivas se sitúan en el ámbito formal. Así, las restrictivas apositivas aparecen enmarcadas entre pausas, mientras que las atributivas carecen de ellas. De manera semejante, el antecedente de las restrictivas atributivas es explícito, en tanto que el de las apositivas está elidido. Pese a estas diferencias formales, D'Introno (1979 y 2001) defiende que, desde el punto de vista semántico, ambos (sub) tipos -atributivas y apositivas- son equivalentes, ya que tanto unas como otras restringen la extensión de su antecedente, diferenciando, en el ejemplo anterior, dos grupos de venezolanos: uno que tiene dinero -y, por tanto, viaja al extranjero-y otro que no. Esta coincidencia semántica se derivaría del hecho de que atributivas y apositivas se generan a partir de una misma estructura sintagmática, con la diferencia de que, en las restrictivas apositivas, se aplicaría posteriormente "una regla de elisión del N presente en el SN o SP yuxtapuesto" (1979, p. 220).

Tanto Ojea López (1992) como Brucart (1999) ${ }^{10}$ aceptan esta propuesta de clasificación, puesto que defienden que "las oraciones de relativo apositivas internamente se configuran como oraciones de relativo libres", y éstas -es decir, las relativas libres- "no son más que cláusulas restrictivas cuyo antecedente carece de realización léxica" (Ojea López 1992, p. 126). En consecuencia, las relativas restrictivas se dividirían en atributivas y apositivas, y la diferencia entre ambas residiría en aspectos formales como la presencia o ausencia de un antecedente expreso. Su función semántica, sin embargo, sería la misma, ya que ambos tipos "restringen la denotación de su antecedente" (Brucart 1999, p. 425), y este rasgo es, por lo demás, el que permite oponerlas a las relativas explicativas o no restrictivas.

J.A. Martínez (1989) también defiende una clasificación tripartita de las oraciones de relativo en la que distingue relativas especificativas (14a), explicativas (14b) y apositivas (14c):

(14) a. Los venezolanos que tienen dinero viajan al extranjero.

$b$. Los venezolanos, que tienen dinero, viajan al extranjero.

c. Los venezolanos, los que tienen dinero, viajan al extranjero.

10 No obstante, BRUCART (1999) prefiere emplear el término pseudoapositiva para así no confundir las relativas apositivas con las relativas explicativas, denominadas por algunos autores como apositivas (LuJÁN 1980). 
No obstante, y a diferencia de los estudiosos anteriores, J.A. Martínez (1989) considera que las relativas apositivas no constituyen un subtipo dentro de las especificativas o restrictivas, sino que conforman una clase propia e independiente. Dicha afirmación se fundamenta en el hecho de que las relativas apositivas, a diferencia de las especificativas y las explicativas, no pertenecen a la categoría adjetiva, sino a la nominal y, por tanto, desempeñan funciones sintácticas propias de esta categoría. Así, las relativas especificativa y explicativa de (14a) y (14b), respectivamente, pueden sustituirse por un adjetivo $(15 a-b)$ y ejercen, por tanto, una función sintáctica propia de esta categoría: adyacente del nombre. La relativa apositiva de (14c), por el contrario, no pertenece a la categoría adjetiva, tal y como demuestra el hecho de que su conmutación conlleva la presencia de un pronombre $(15 c)$ y no así de un adjetivo:

(15) a. Los venezolanos adinerados viajan al extranjero.

b. Los venezolanos, adinerados, viajan al extranjero.

c. Los venezolanos, aquéllos, viajan al extranjero.

En consecuencia, la función sintáctica de una relativa apositiva no es la de adyacente, sino que desempeña la misma función que el segmento con el que aparece en aposición. En el ejemplo (14c), los dos segmentos en aposición son el sintagma los venezolanos y la oración relativa los que tienen dinero. Puesto que los venezolanos funciona como sujeto, esta misma función sintáctica corresponde a la relativa apositiva.

A pesar de estas diferencias sintácticas, J.A. Martínez considera que las relativas apositivas, al igual que las especificativas, "puede [n] restringir o especificar lo referido por el antecedente" (1989, p. 177). En este sentido, el criterio semántico de la restricción del antecedente permitiría diferenciar las relativas especificativas y apositivas de las explicativas, mientras que las especificativas y explicativas se diferenciarían de las apositivas a partir del criterio de la categoría sintáctica y, en consecuencia, de las funciones sintácticas que unas y otras oraciones pueden ejercer.

Iglesias Bango (2003) recoge el testigo de J.A. Martínez (1989) e incide especialmente en la necesidad de no confundir los conceptos de categoría gramatical -o morfológica- y categoría funcional -o sintáctica. Así, para Iglesias Bango, la clasificación de las oraciones de relativo en especificativas y expli- 
cativas tiene sentido cuando éstas funcionan como adyacente de un nombre y, por lo tanto, son equivalentes a sintagmas adjetivos; sin embargo, cuando éstas equivalen a sintagmas nominales o adverbiales, no es posible aplicar dicha tipología. Es por ello por lo que Iglesias Bango defiende, al igual que J.A. Martínez, que las relativas apositivas constituyen un tercer tipo de oraciones relativas. No obstante, y a diferencia de Martínez, considera que no todas ellas se encuentran en la misma posición de jerarquía. Concretamente, Iglesias Bango hace una primera distinción de las oraciones de relativo en apositivas y no apositivas atendiendo al criterio de la equivalencia: las primeras se caracterizan por que los dos segmentos en aposición -es decir, el "antecedente" 11 y la oración de relativo- "se encuentran categorial y funcionalmente igualados" (2003, p. 77), como en $(16 a)$, mientras que en las relativas no apositivas no habría tal equivalencia en ninguno de los dos niveles (16b):

(16) a. Tus amigos, los que me prestaron el libro, son muy simpáticos.

b. Los chicos que me prestaron el libro son muy simpáticos.

Así, los dos segmentos en aposición de (16a) -tus amigos y los que me prestaron el libro- pertenecen a la categoría nominal, como demuestra el hecho de que la oración relativa pueda sustituirse por un pronombre (17a). De manera semejante, ambos segmentos desempeñan la función sintáctica de sujeto, ya que, por un lado, concuerdan en número y persona con el verbo de la oración principal $(17 b)$ y, por otro, pueden contraer dicha función por separado $(17 c-d)$ :

(17) a. Tus amigos, ellos, son muy simpáticos.

b. Tu amigo, el que me prestó el libro, es muy simpático.

c. Tus amigos son muy simpáticos.

$d$. Los que me prestaron el libro son muy simpáticos.

Por el contrario, en (16b) no hay tal equivalencia, puesto que, desde el punto de vista categorial, el antecedente -los chicos- es un sintagma nominal, y la oración relativa -que me pres-

11 Al igual que Iglesias BAngo (2003), empleamos comillas, ya que el sintagma que precede a la relativa apositiva no constituye realmente su antecedente sintáctico, sino un segmento que indica el significado que se le debe otorgar a la relativa apositiva. 
taron el libro-, un sintagma adjetival (18a). Desde un punto de vista funcional, el antecedente desempeña la función de núcleo del sujeto, y la oración relativa, la de adyacente de ese núcleo, por lo que no puede aparecer sin el segmento al que modifica $(18 b)$ :

(18) a. Los chicos generosos son muy simpáticos.

b. *Que me prestaron el libro son muy simpáticos.

Iglesias Bango (2003) se apoya, por tanto, en criterios formales para establecer una primera clasificación de las oraciones de relativo en apositivas y no apositivas. A esta primera distinción sobrepone una segunda que afectaría solamente a aquellas relativas no apositivas que constituyan sintagmas adjetivos y funcionen como adyacentes nominales: éstas se subdividirían en especificativas y explicativas a partir del criterio semántico de la restricción del antecedente.

Pese a ciertas diferencias, vemos que las clasificaciones de las oraciones de relativo definidas como tripartitas se basan en una combinación de criterios: de este modo, los criterios formales permiten distinguir las relativas apositivas del resto de oraciones de relativo, en tanto que la diferencia entre relativas especificativas $-\mathrm{O}$ restrictivas- y explicativas $-\mathrm{O}$ no restrictivasse apoya en criterios semánticos.

La Tabla 1 resume las principales clasificaciones tripartitas de las oraciones de relativo en lengua española, y quizá la diferencia más notable entre unas y otras resida en el hecho de considerar o no a las relativas apositivas como un tipo distinto de oración de relativo. Mientras que D'Introno (1979 y 2001), Ojea López (1992) y Brucart (1999) consideran que las apositivas se integran como un subtipo en las relativas restrictivas, J.A. Martínez (1989) e Iglesias Bango (2003) argumentan que las apositivas difieren tanto de las especificativas como de las explicativas -independientemente de que estas tres ocupen o no la misma jerarquía. Las discrepancias entre estas clasificaciones no se deben tanto a los criterios empleados -ya que unos y otros autores trabajan con criterios semánticos y sintácticos-, sino, más bien, al hecho de analizar estas construcciones desde perspectivas diferentes (Brucart 1999).

D’Introno (1979 y 2001), Ojea López (1992) y Brucart (1999) reconocen que las relativas apositivas mantienen una relación de aposición con un primer componente -los venezo- 
TABla 1

Clasificaciones tripartitas de las oraciones relativas

\begin{tabular}{|c|c|c|c|}
\hline Autor & \multicolumn{2}{|c|}{ Clasificación } & Ejemplo \\
\hline \multirow{3}{*}{$\begin{array}{c}\text { D'Introno } \\
\text { (1979 y 2001); } \\
\text { Ojea López } \\
\text { (1992); } \\
\text { Brucart (1999) }\end{array}$} & \multirow[b]{2}{*}{ Restrictivas } & Atributivas & $\begin{array}{l}\text { Los venezolanos que tienen } \\
\text { dinero viajan al extranjero }\end{array}$ \\
\hline & & Apositivas & $\begin{array}{l}\text { Los venezolanos, los que } \\
\text { tienen dinero, viajan al } \\
\text { extranjero }\end{array}$ \\
\hline & \multicolumn{2}{|c|}{ No restrictivas } & $\begin{array}{l}\text { Los venezolanos, que tienen } \\
\text { dinero, viajan al extranjero }\end{array}$ \\
\hline \multirow{3}{*}{$\begin{array}{l}\text { J.A. Martínez } \\
\text { (1989) }\end{array}$} & \multicolumn{2}{|c|}{ Especificativas } & $\begin{array}{l}\text { Los venezolanos que tienen } \\
\text { dinero viajan al extranjero }\end{array}$ \\
\hline & \multicolumn{2}{|c|}{ Explicativas } & $\begin{array}{l}\text { Los venezolanos, que tienen } \\
\text { dinero, viajan al extranjero }\end{array}$ \\
\hline & \multicolumn{2}{|c|}{ Apositivas } & $\begin{array}{l}\text { Los venezolanos, los que } \\
\text { tienen dinero, viajan al } \\
\text { extranjero }\end{array}$ \\
\hline \multirow{3}{*}{$\begin{array}{c}\text { Iglesias Bango } \\
(2003)\end{array}$} & \multicolumn{2}{|c|}{ Apositivas } & $\begin{array}{c}\text { Los venezolanos, los que } \\
\text { tienen dinero, viajan al } \\
\text { extranjero }\end{array}$ \\
\hline & \multirow{2}{*}{$\begin{array}{l}\text { No apositivas } \\
\quad(\text { de } \mathrm{CN})\end{array}$} & Especificativas & $\begin{array}{l}\text { Los venezolanos que tienen } \\
\text { dinero viajan al extranjero }\end{array}$ \\
\hline & & Explicativas & $\begin{array}{l}\text { Los venezolanos, que tienen } \\
\text { dinero, viajan al extranjero }\end{array}$ \\
\hline
\end{tabular}

lanos en (12a) o los estudiantes en (12b) - y que, por tanto, tales oraciones constituyen sintagmas nominales. Sin embargo, el interés de estos autores no se centra en analizar la relación de aposición entre esos dos segmentos, sino la composición interna del segundo de ellos, con independencia del primero. Ese segundo segmento está formado por un artículo seguido de una oración de relativo introducida por que, en la que el antecedente nominal ha sido elidido. No obstante, dicho antecedente podría recuperarse fácilmente (19), de tal forma que la estructura resultante sería equivalente a una relativa especificativa o restrictiva no sólo desde un punto de vista formal, sino también semántico, ya que denota a un grupo concreto de venezolanos: aquellos que tienen dinero. Es por ello por lo que 
D’Introno (1979 y 2001), Ojea López (1992) y Brucart (1999) defienden que las relativas apositivas "no constituyen un patrón particular dentro de la clase de las relativas, sino que son oraciones especificativas que modifican al núcleo elíptico" (Brucart 1999, p. 427).

(19) Los venezolanos, los que tienen dinero, viajan al extranjero.

los venezolanos que tienen dinero

J.A. Martínez (1989) e Iglesias Bango (2003), en cambio, analizan las relativas apositivas desde una perspectiva más externa, ya que para ellos lo relevante de estas construcciones es el hecho de que, al aparecer en aposición con un primer segmento, deben pertenecer a la misma categoría funcional. Así, si el primer segmento -los venezolanos- es un sintagma nominal, el segundo -los que tienen dinero- también debe serlo, dado que, en caso contrario, no se podría establecer una relación de aposición entre ellos. En consecuencia, no se puede considerar que la oración relativa de ese segundo segmento sea especificativa o explicativa, pues ésta es una distinción propia de los adjetivos y, por tanto, no se debe aplicar a unidades que no lo sean.

\section{Problemas de las CLASIFICACIONES}

DE LAS ORACIONES DE RELATIVO

En el apartado anterior hemos presentado diversas clasificaciones de las oraciones de relativo atendiendo a criterios semánticos, sintácticos, así como a una combinación de ambos. De manera semejante, hemos establecido equivalencias terminológicas entre ciertas clasificaciones, pues algunos autores emplean denominaciones diferentes para hacer referencia a una misma realidad -por ejemplo, especificativa y restrictiva, o explicativa y no restrictiva-, mientras que otros emplean el mismo término para realidades dispares - por ejemplo, el término relativa apositiva como equivalente de las explicativas o de las pseudoapositivas según la terminología de Brucart (1999). Partiendo de las clasificaciones previas, en el apartado subsiguiente describiremos varios de los problemas detectados con el objetivo de buscarles una solución a la hora de proponer una clasificación propia de las oraciones de relativo. 
Generalmente, las clasificaciones semánticas parten del criterio de la restricción del antecedente para diferenciar dos tipos de oraciones de relativo: especificativas (o restrictivas) vs. explicativas (o no restrictivas, apositivas). No obstante $-y$ pese a la gran aceptación que esta tipología ha tenido en las obras gramaticales del español-, es importante conocer sus limitaciones, centrándonos en este subapartado en dos de ellas.

Con gran frecuencia, los principales gramáticos españoles del siglo $\mathrm{xx}$ han compaginado el criterio semántico de la restricción del antecedente con un criterio formal, como la pausa, a la hora de diferenciar relativas especificativas y explicativas (Bello 1978 [1847]; Gili Gaya 1961; Marcos Marín 1980; RAE 1973; Alcina y Blecua 1975; Alarcos 1994; Matte Bon 1995 [1992]). Sin embargo, la combinación de estos dos criterios puede resultar problemática, pues hay numerosas muestras en el habla real en las que no concuerdan (Aletá Alcubierre 1990; Porto Dapena 1997; RAE y ASALE 2009). Por ejemplo, la oración relativa de (20) se clasificaría como explicativa según el criterio formal de la pausa, ya que aparece enmarcada entre comas; sin embargo, si atendemos a su función semántica, dicha oración estaría lejos de considerarse como explicativa, pues, en este caso, la oración relativa no añade ninguna información adicional sobre el referente, sino que, por el contrario, restringe la clase designativa de los participantes y acompañantes, diferenciando dos grupos: uno que desea asistir y otro que no. Por consiguiente, la función semántica de (20) es propia de las relativas especificativas, y no concuerda, por tanto, con el criterio formal de la pausa:

(20) Los participantes y acompañantes, que lo deseen, podrán asistir a los actos sociales (CREA, Física y sociedad [Esp.], 2002).

Podemos encontrarnos, asimismo, con la situación opuesta: la oración relativa de (21) no está situada entre pausas, lo que llevaría a considerarla como especificativa según este criterio. No obstante, su función semántica no es la de restringir el referente de su antecedente -de hecho, éste está perfectamente identificado antes de la oración relativa-, sino que añade cierta información adicional sobre él: 
(21) Podemos mencionar a John Byron, George Vancouver, James Cook y Francis Drake que estuvo libre de escorbuto durante tres años (CREA, Odiseo [Esp.], 2001).

Más allá de la falta de concordancia entre los criterios de la restricción del antecedente y de la pausa, la clasificación tradicional de las oraciones de relativo en especificativas y explicativas se encuentra con un segundo problema quizá más importante: el paralelismo que se suele establecer entre los conceptos de especificativa y restrictiva y, por ende, de explicativa y no restrictiva (Gili Gaya 1961; Marcos Marín 1980; RAE 1973; Alcina y Blecua 1975; Bello 1978 [1847]; D'Introno 1979 y 2001; Alarcos 1994; Matte Bon 1995 [1992]; Porto Dapena 1997). Así, las relativas especificativas se suelen definir como aquellas oraciones que "determinan al antecedente, especificándolo, restringiéndolo" (RAE 1973, p. 525), lo que ha llevado a generalizar la idea de que todas las relativas especificativas restringen. Este hecho es cierto en casos como el de (22), en que la oración relativa diferencia dos grupos de inmigrantes: uno que cruza el Canal de la Mancha y otro que cruza o viaja por vías alternas; el primero de ellos es, evidentemente, el denotado por medio de la oración de relativo:

(22) En el condado de Kent reparten un panfleto electoral equiparando a los inmigrantes que cruzan el Canal de la Mancha con delincuentes comunes (CORPES XXI, Diario de Londres [Esp.], 2001).

Sin embargo, hay numerosas oraciones de relativo que, pese a clasificarse como especificativas, no cumplen el requisito de la restricción. Uno de los autores que con mayor profundidad ha estudiado este problema es Aletá Alcubierre (1990), quien, a partir de oraciones como (23), muestra la diferencia entre los conceptos de especificativa y restrictiva.

(23) En la calle sólo había un crío que jugaba a la pelota.

Si bien es cierto que la oración relativa de (23) puede ser restrictiva en un contexto en el que hubiese más de un crío en la calle - de tal forma que ésta diferenciaría a aquel que juega con la pelota de aquellos otros que no lo hacen-, ¿qué ocurriría en un contexto en el que hubiese un único crío en la calle? 
En este caso, la oración de relativo no puede restringir, ya que no es posible diferenciar a ese crío de otros (principalmente porque esos otros no existirían). La función de la oración relativa no sería ahora la de restringir el referente de su antecedente, sino la de identificarlo. Es por ello por lo que Aletá Alcubierre (1990) considera que no se deben confundir, como se ha hecho tradicionalmente, los conceptos de especificativa y restrictiva, pues una relativa especificativa solamente puede ejercer restricción si el universo del discurso está constituido por más de un individuo. Se vuelve, por tanto, indispensable conocer el contexto comunicativo en el que se emite una oración de relativo para determinar si ésta restringe o simplemente identifica el referente de su antecedente.

RAE y ASALE $(2009, \S 44.6)$ también recogen esta crítica en su NGLEy definen ciertos contextos sintáctico-semánticos en los que es posible dudar de la interpretación restrictiva de una relativa especificativa. Uno de esos contextos sería el que aparece representado en el ejemplo (23), es decir, enunciados en los que la oración relativa modifica a un antecedente formado por un grupo nominal indeterminado en posición posverbal. A este contexto habría que sumar un segundo correspondiente con aquellos casos en los que la oración relativa introduce una valoración subjetiva sobre su antecedente, como en (24):

(24) Hay, sin embargo, una excepción que me parece extraordinariamente interesante (RAE y ASALE 2009, § 44.6b).

Hay un tercer contexto en el que también es posible cuestionarse la función restrictiva de una relativa especificativa: cuando una oración aparece con un verbo de existencia -por ejemplo, haber o ser-y sin aditamentos que lo modifiquen. Así, la oración relativa de (25a) no puede diferenciar la silla que había de otras sillas que no hubiese, ya que éstas otras no existirían. La situación sería diferente si el verbo de la oración relativa estuviese complementado por un aditamento, como en (25b), dado que, en este caso, sí sería posible diferenciar la silla que está en la habitación de otras sillas que estuviesen en otra parte de la casa:

(25) a. La silla que había era de mimbre destartalado (CREA, Weblog [Esp.], 2004).

$b$. La silla que había en la habitación era de mimbre destartalado. 
RAE y ASALE no recogen este tercer contexto en su obra de 2009, pero sí aparece descrito en trabajos previos, como el de Alcina y Blecua (1975, p. 1037), quienes denominaron a este tipo de oraciones especificativas redundantes. Estos ejemplos ponen de manifiesto, por tanto, que no toda relativa especificativa restringe la extensión de su antecedente y que, en consecuencia, no es adecuado establecer un completo paralelismo entre los conceptos de especificativa y restrictiva.

Ante esta situación, Aletá Alcubierre (1990; también véase Marcos Marín et al. 1998) propone una nueva clasificación de las oraciones de relativo basada en dos oposiciones semántico-pragmáticas: $a$ ) especificativa $v s$. explicativa y $b$ ) restrictiva vs. no restrictiva. Así, una oración especificativa es aquella que identifica el referente designado por el antecedente, mientras que una oración explicativa no identifica el referente del antecedente -pues éste ya está identificado-, sino que expresa una nota definitoria del mismo. Por su parte, una oración restrictiva es aquella que restringe la extensión de su antecedente, por lo que el universo del discurso debe estar formado por más de un elemento; una oración no restrictiva, en cambio, no restringe, sino que hace referencia a todos los elementos que integran el universo del discurso al que se refiere el antecedente. La combinación de estas notas permite diferenciar cuatro tipos de oraciones de relativo, que Aletá Alcubierre (1990, pp. 162163) ejemplifica de la siguiente manera:

(26) a. Especificativa-restrictiva: había un crí que jugaba a la pelota (en un contexto en el que haya varios críos).

b. Especificativa-no restrictiva: había un crío que jugaba a la pelota (en un contexto en el que haya un solo crío).

c. Explicativa-restrictiva: hoy en día, un crío, que disponga de dinero, claro está, se recorre el mundo.

$d$. Explicativa-no restrictiva: un crío, que tiene toda la vida por delante, no tiene por qué preocuparse de esas cosas.

No cabe duda de que, tal y como demuestra Aletá Alcubierre, una relativa especificativa puede identificar el referente de un antecedente por medio de una restricción de su clase designativa $(26 a)$ o por otros medios que no conlleven, necesariamente, una restricción (26b). No obstante, es posible cuestionarse si esta misma distinción entre restrictiva y no restrictiva se podría aplicar a las oraciones explicativas $(26 c-d)$, pues unas 
y otras presentan rasgos semánticos que podrían considerarse contradictorios.

Así, Aletá Alcubierre define las relativas explicativas como aquellas cuyo antecedente está identificado de manera previa a la introducción de la oración de relativo: "El hablante en este caso supone que ese referente ya está identificado" (p. 160). Por su parte, las relativas restrictivas se definen como aquellas que restringen la extensión de su antecedente, diferenciando dos grupos de entidades: uno que cumple la restricción predicada por la relativa -y que será el designado- y otro que no. Si la función de una relativa restrictiva es, por tanto, la de designar uno de esos grupos, ello quiere decir que el antecedente no puede estar identificado de manera previa a la introducción de la oración de relativo, característica que, por lo demás, define a una relativa explicativa. En consecuencia, las relativas explicativas y las relativas restrictivas parecen presentar rasgos semánticopragmáticos incompatibles, ya que, a priori, no sería posible restringir aquello que ya está identificado.

Los aspectos revisados en este subapartado permiten, por tanto, establecer dos conclusiones claras acerca de las clasificaciones de las oraciones de relativo basadas en criterios semánticos. En primer lugar, el criterio semántico de la restricción del antecedente no siempre concuerda con uno de índole formal como son las pausas. Por ende, es importante definir a cuál de estos dos criterios -semántico o formal- se debe dar mayor relevancia en casos de incongruencia. Además, está claro que no todas las relativas especificativas restringen la extensión de su antecedente, por lo que no resulta adecuado establecer un perfecto paralelismo entre estos dos conceptos, aspecto que, sin embargo, ha caracterizado a un gran número de obras gramaticales del español. Una buena clasificación de las oraciones de relativo pasaría, por tanto, por una revisión de los conceptos de "especificativa $v s$. explicativa" y "restrictiva $v s$. no restrictiva”, ante los que sería posible proponer dos soluciones: o bien se modifican los rasgos semánticos que definen a las relativas especificativas - de tal forma que la restricción no sea su nota definitoria-, o bien se diferencia un mayor número de oraciones relativas -especificativas-restrictivas y especificativas-no restrictivas. Aletá Alcubierre (1990) apuesta por esta segunda opción, en tanto que RAE y ASALE más bien parecen inclinarse por la primera. Así, en la NGLE se considera que la función esencial de una relativa especificativa no es la de restringir, sino 
la de "precisar la denotación del grupo nominal del que forma parte" (2009, § 44.1n).

\section{Problemas de las clasificaciones sintácticas}

Como ha podido comprobarse previamente, no son muchas las clasificaciones que se han realizado de las oraciones de relativo a partir de criterios exclusivamente sintácticos y, en la mayoría de los casos, éstas se encuentran fuertemente condicionadas por la tipología semántica que opone las relativas especificativas a las explicativas (Roca-Pons 1960). La propuesta más original a este respecto es la establecida por Porto Dapena (1997), quien, en función del segmento del que dependiese la oración relativa, diferenció entre integradas y no integradas. Esta clasificación resulta adecuada en un gran número de casos -por ejemplo, (6) y (7)-; sin embargo, también es posible encontrarse ante situaciones de dudosa consideración. Brucart (1999) señala como muestra de ello la oración de (27), en que "la remisión a un antecedente oracional en la relativa no siempre implica la inclusión de todos los elementos de la correspondiente oración matriz" (p. 438). Así, el antecedente de la oración relativa de (27) sería el hecho de abandonar la reunión; pero no se incluiría como parte de tal antecedente el sujeto de la oración principal, Luis. Ante esta situación, cabría cuestionarse si estamos frente a una relativa integrada -en cuyo caso el antecedente no sería el único constituyente de la oración relativa, sino varios (abandonó la reunión) - o si, por el contrario, estamos frente a una relativa no integrada, que dependería de un gran número de constituyentes de la oración principal, pero no de todos. Tanto si se opta por una posibilidad como por la otra, se hace necesaria una revisión de los conceptos de relativa integrada y no integrada con el propósito de determinar hasta qué punto el antecedente de (27) es o no oracional.

(27) Luis abandonó la reunión, lo que también hizo Antonio.

Problemas de las oraciones con "donde", "cuando" y "como". En relación con las clasificaciones basadas en criterios sintácticos, véase supra el análisis que hicimos en el subapartado "Oraciones con donde, cuando y como". No todos los gramáticos consideran que las estructuras introducidas por estas unidades constituyan ora- 
ciones de relativo -especialmente cuando no hay un antecedente nominal expreso-, pues suelen desempeñar la función sintáctica de aditamento, asociada tradicionalmente a los sintagmas adverbiales. Es por ello por lo que, en un gran número de clasificaciones, las estructuras introducidas por donde, cuando y como se sitúan entre las oraciones subordinadas adverbiales, y no así entre las relativas (Gili Gaya 1961; RAE 1973; Marcos Marín 1980; J.A. Martínez 1989; Alarcos 1994). Ante esta cuestión, debemos considerar varios factores.

En primer lugar, no es correcto asociar únicamente la categoría adverbial con la función de aditamento, pues son numerosos los casos en los que un sintagma nominal también puede desempeñar esta función -por ejemplo, (11). Por lo tanto, no parece un argumento satisfactorio considerar que las oraciones introducidas por donde, cuando o como son subordinadas adverbiales por el simple hecho de que, con gran frecuencia, ejercen la función de aditamento (Alarcos 1982 [1970]; J.A. Martínez 1989; Brucart 1999; RAE y ASALE 2009).

En segundo, es importante tener en cuenta que las oraciones introducidas por dichas unidades no sólo funcionan como aditamentos, sino que también pueden desempeñar, aunque con menor frecuencia, otras funciones sintácticas -por ejemplo, implemento (o complemento directo) en (28)-, asociadas éstas a la categoría nominal (Alarcos 1982 [1970]; Brucart 1999; RAE y ASALE 2009).

(28) $a$. Vi donde se reunieron.

b. Aún recuerdo cuando leíste el discurso de graduación.

c. Ignora a Juan y como te trata.

Partiendo de estos postulados, la cuestión a considerar es si solamente se deben analizar como oraciones de relativo aquellas estructuras que funcionen como adjetivos o si, por el contrario, dentro de esta categoría también se deben incluir aquellas oraciones que, pese a no funcionar como adjetivos, son introducidas por alguna de las unidades que forman parte del paradigma de los relativos. Obviamente, la respuesta a esta cuestión dependerá de la definición que manejemos de oración de relativo; pero, en cualquiera de los casos, debe aplicarse de forma sistemática. Éste es, precisamente, uno de los problemas que se detecta en las gramáticas hispánicas, en las que suele identificarse el concepto de oración de relativo con el de subordinada 
adjetiva. Ello ha llevado a considerar que oraciones como las de (9) -repetidas aquí como (29) - no son relativas, sino subordinadas adverbiales, ya que equivaldrían a sintagmas de este tipo.

(29) a. Coloqué los libros donde estaban.

$b$. Cuando llegaron se había desatado una fuerte tormenta.

c. Resolvió el ejercicio como le había explicado el profesor.

No obstante, en esas mismas obras gramaticales se suele incluir entre las oraciones de relativo estructuras como la de (30a), cuya categoría sintáctica tampoco es la adjetiva, sino la nominal, tal y como demuestra su conmutación por un sustantivo $(30 b)$ :

(30) a. Quien bien te quiere te hará llorar.

$b$. Esa persona te hará llorar.

La cuestión que, por tanto, uno se plantea es por qué estructuras como la de (30a) sí se analizan como oraciones de relativo, pero no otras, como las de (29), cuando ni unas ni otras equivalen a un adjetivo. Así pues, si se establece una identificación entre oración de relativo y subordinada adjetiva, ésta debe aplicarse de manera sistemática y no sólo en determinados contextos.

\section{Problemas de las clasificaciones tripartitas}

En el subapartado "Combinación de criterios..." se presentaron diversas propuestas tripartitas de clasificación de las oraciones de relativo motivadas por la inclusión de las relativas apositivas como un tipo o subtipo de estas estructuras. Sin embargo, es posible señalar ciertos aspectos que deberían ser objeto de revisión en dichas clasificaciones.

Fundamentalmente, los autores de las diferentes propuestas tripartitas aceptan que las relativas apositivas como (12a) -repetida aquí como (31a) - o (12b) -repetida aquí como (31b) - conforman sintagmas nominales, tal y como demuestra el hecho de que puedan sustituirse por un pronombre $(31 c-d)$ :

(31) a. Los venezolanos, los que tienen dinero, viajan al extranjero.

b. Tus amigos, los que me prestaron el libro, son muy simpáticos. 
c. Los venezolanos, aquéllos, viajan al extranjero.

$d$. Tus amigos, ésos, son muy simpáticos.

Dada su categoría funcional, J.A. Martínez (1989) e Iglesias Bango (2003) defienden que no es posible aplicar la distinción "especificativa $v s$. explicativa", propia de los adjetivos, a las relativas apositivas, razón por la que sitúan tales oraciones fuera de estos dos tipos. Estamos de acuerdo con ambos autores en la importancia de identificar correctamente la categoría funcional de un sintagma y las consecuencias que ello puede desencadenar a la hora de analizar dicha unidad. Por este motivo, no parece adecuado aplicar clasificaciones propias de la categoría adjetiva a unidades que no lo son. No obstante, la estructura prototípica de las relativas apositivas -artículo + que - no aparece solamente en este tipo de construcciones, sino que también es frecuente en estructuras focalizadas (32a) o, simplemente, como funtivo que desempeña una función sintáctica en una estructura no focalizada (32b):

(32) $a$. En la práctica es toda la sociedad la que tiene que asumir la necesidad de preservar la naturaleza (CREA, Vida. La naturaleza en peligro [Esp.], 2001).

$b$. Creo que los que ya tienen su casa no renunciarán a que la tengan otros vecinos (CREA, La voz de Asturias [Esp.], 2004).

Pese a no aparecer en aposición con otro segmento del enunciado, las oraciones relativas de (32) también están formadas por la estructura "artículo + que" y pertenecen a la categoría nominal. Ello implica que este tipo de estructuras no es exclusivo de las relativas apositivas, sino que puede aparecer en construcciones de diversa naturaleza. El problema que surge a este respecto es dónde situar estas construcciones dentro de las clasificaciones de las oraciones de relativo previamente revisadas.

Por un lado, J.A. Martínez (1989) e Iglesias Bango (2003) son conscientes de la existencia de estructuras como (32); sin embargo, ninguno de ellos las recoge de manera explícita en sus propuestas. Así, en la clasificación de J.A. Martínez, estas estructuras no tendrían cabida, pues, al no pertenecer a la categoría adjetiva, no se podrían considerar ni como especificativas ni como explicativas; no obstante, tampoco pueden analizarse como apositivas, ya que -pese a ser sintagmas nominales- no 
mantienen una relación de aposición con ningún otro segmento del enunciado. En cuanto a Iglesias Bango, las oraciones relativas de (32) se clasificarían como no apositivas; sin embargo, dentro de esta categoría no sería posible diferenciarlas de otras oraciones relativas que, siendo igualmente no apositivas, no constituyan sintagmas nominales.

Por otro lado, Ojea López (1992), Brucart (1999) o RAE y ASALE (2009), por ejemplo, denominan a las relativas incluidas en los ejemplos de (32) relativas semilibres y las definen como "relativas especificativas que carecen de antecedente nominal explícito" (RAE y ASALE 2009, § 44.7a). Tal propuesta concuerda con la que estos autores plantean para las relativas apositivas -es decir, las relativas semilibres y apositivas presentan los mismos rasgos sintácticos y semánticos y, en consecuencia, ambas se consideran especificativas-; sin embargo, incurre en la problemática previamente descrita de aplicar una tipología propia de los adjetivos a unidades que no lo son. A este problema, habría que añadir un segundo: tanto D'Introno (1979 y 2001) como Ojea López o Brucart caracterizan a las relativas apositivas y semilibres como especificativas, porque en ellas el antecedente elidido puede ser recuperado fácilmente, y dar como resultado una oración que, tanto desde el punto de vista formal como semántico, equivale a una restrictiva. Si bien es cierto que la recuperación de ese antecedente es posible en construcciones como (33), son, asimismo, frecuentes los casos en los que la recuperación de un antecedente no es posible sin que la oración resultante sea agramatical $(34 b-c)$ o sin llevar a cabo ciertas modificaciones sobre el enunciado original (34d-e). Ante estos problemas, D’Introno, Ojea López y Brucart no aportan ninguna explicación.

(33) a. Los venezolanos, los [venezolanos] que tienen dinero, viajan al extranjero.

b. Los [vecinos] que ya tienen su casa no renunciarán a que la tengan otros vecinos.

(34) a. Come lo que quieras.

b. *Come lo [pastel] que quieras.

c. *Come lo [cantidad] que quieras.

$d$. Come $e l$ [pastel] que quieras.

e. Come la [cantidad] que quieras. 
Teniendo en cuenta los aspectos comentados en este último subapartado, es posible concluir que $a$ ) la estructura de las relativas apositivas "artículo + que" no es exclusiva de estas construcciones, sino que puede aparecer en muchas otras -conocidas, generalmente, como relativas semilibres-, por lo que se vuelve necesario incluirlas en una clasificación de las oraciones de relativo (J.A. Martínez 1989; Iglesias Bango 2003); b) tanto las relativas apositivas como las semilibres constituyen sintagmas nominales, por lo que no es posible aplicar en ellas la distinción "especificativa $v s$. explicativa" propia de los sintagmas adjetivales, tal y como hacen, entre otros, Brucart (1999) o RAE y ASALE (2009).

\section{Propuesta DE CLASIFICACión DE LAS ORACIONES DE RELATIVO}

El apartado "Clasificaciones previas..." recoge diversos agrupamientos de las oraciones de relativo que atienden tanto a criterios semánticos como sintácticos, así como a una combinación de ambos. Sin embargo, los inconvenientes que estas distribuciones presentan, recogidos en el apartado "Problemas de las clasificaciones...", nos invitan a plantear una nueva propuesta con el objetivo no sólo de solventar sus limitaciones, sino también de incorporar -en una clasificación de este tipo- todas aquellas estructuras que, con bastante frecuencia, no han sido incluidas en las clasificaciones anteriores de las oraciones de relativo. En la mayoría de los casos, esta ausencia no se debe a un desconocimiento por parte de los autores, pues, aunque no incorporen estas estructuras de manera explícita en sus propuestas, sí las analizan en apartados independientes (Bello 1978 [1847]; Gili Gaya 1961; RAE 1973; Alcina y Blecua 1975; Alarcos 1994; Porto Dapena 1997; Brucart 1999; RAE y ASALE 2009). Por el contrario, es posible que el hecho de no incluir esos otros tipos de estructuras con relativos en sus clasificaciones esté más bien relacionado con el apego a la tipología bipartita tradicional.

Así pues, debemos comenzar señalando que nuestra propuesta se desarrollará según la perspectiva de la gramática funcional (Alarcos 1982 [1970]; Gutiérrez Ordóñez 1997; Iglesias Bango 2003) y tomando como punto de partida la definición que De Vries (2002) ofrece de oración de relativo: estructura caracterizada por a) ser un segmento subordinado y por b) com- 
partir con la oración principal un elemento pívot. En español, la forma plena de ese pívot aparece en la oración principal, mientras que, en la oración relativa, se manifiesta mediante un pronombre relativo (Moreno Cabrera 1991).

Las oraciones de relativo prototípicas -es decir, aquellas que equivalen a adjetivos- cumplen estas dos características, pues a) están subordinadas a un sustantivo, de tal forma que su elisión da lugar a una estructura agramatical si no hay un determinante que la sustantive (35b-c); y porque $b$ ) el elemento pívot se manifiesta en la oración principal por medio del sustantivo y en la oración relativa por medio de un pronombre relativo $(35 d)$ :

(35) a. El alumno que no estudie suspenderá.

b. *Que no estudie suspenderá.

c. El que no estudie suspenderá.

$d$. El alumno ${ }_{\mathrm{i}}\left[\right.$ que $_{\mathrm{i}}$ no estudie] suspenderá.

No obstante, estos dos requisitos no sólo se satisfacen cuando el antecedente de la oración relativa es un sustantivo, sino también un adjetivo (36) o un adverbio (37), estructuras que, generalmente, no se incluyen en las clasificaciones de las oraciones de relativo (J.A. Martínez 1989):

(36) $a$. Me sorprendió lo joven que era.

b. *Me sorprendió que era.

c. ?Me sorprendió lo que era.

$d$. Me sorprendió lo joven ${ }_{\mathrm{i}}\left[\mathrm{que}_{\mathrm{i}}\right.$ era] .

(37) a. Lo felicitó por lo lejos que había llegado.

$b$. *Lo felicitó por que había llegado.

c. ?Lo felicitó por lo que había llegado.

$d$. Lo felicitó por lo lejos [que $_{\mathrm{i}}$ había llegado].

¿Qué ocurre, por su parte, con las relativas libres (38) y semilibres (39)? Es cierto que éstas carecen de un antecedente explícito, pero ello no quiere decir que la oración encabezada por el relativo no esté subordinada; lo está, pero, en este caso, al verbo de la oración principal, de tal forma que su elisión genera una estructura que, si bien no es agramatical, sí resulta anómala sin un contexto comunicativo específico (38-39b):

(38) a. Quien no estudie suspenderá.

b. ?Quien no estudie. 
(39) a. El que no estudie suspenderá.

b. ?El que no estudie.

Por lo demás, el hecho de que las relativas libres y semilibres carezcan de un antecedente expreso no implica que en este tipo de oraciones no haya un elemento pívot compartido con la oración principal. Al contrario, ese elemento pívot se manifiesta mediante un pronombre relativo en la oración relativa -ya sea libre o semilibre-, en tanto que, en la oración principal, equivale al sintagma nominal conformado por la propia oración de relativo que ejerce una función dentro de la oración principal (40):

(40) a. [Quien ${ }_{\mathrm{i}}$ no estudie $]_{\mathrm{i}}$ suspenderá. $^{2}$

b. $\left[\text { El que }{ }_{\mathrm{i}} \text { no estudie }\right]_{\mathrm{i}}$ suspenderá.

Ambos requisitos se cumplen, asimismo, en aquellas relativas libres encabezadas por las unidades donde, cuando o como (41):

(41) a. Coloqué los libros donde estaban.

$b$. ?Los libros donde estaban.

c. Coloqué los libros $\left[\right.$ donde $_{\mathrm{i}}$ estaban $_{\mathrm{i}}$.

Partiendo, por tanto, de esta definición de oración de relativo, plantearemos una clasificación que incluya todas aquellas estructuras que satisfagan tales requisitos. Concretamente, emplearemos como criterio de clasificación la categoría funcional del sintagma compuesto por estas oraciones. Así pues, las oraciones relativas pueden clasificarse en tres tipos en función de su categoría sintáctica.

1. Relativas adjetivas: son aquellas que equivalen categorialmente a adjetivos, como prueba el hecho de que puedan sustituirse por palabras de esta categoría gramatical (42-43b). Como consecuencia de ello, estas oraciones desempeñan funciones sintácticas propias de los adjetivos, fundamentalmente, la de adyacente nominal:

(42) a. En el condado de Kent reparten un panfleto electoral equiparando a los inmigrantes que cruzan el Canal de la Mancha con delincuentes comunes (CORPES XXI, Diario de Londres [Esp.], 2001). 
$b$. En el condado de Kent reparten un panfleto electoral equiparando a los inmigrantes ilegales con delincuentes comunes.

(43) a. Los vecinos de Getxo, que se concentraron la tarde del pasado día 18 para repudiar el último atentado de ETA, gritaron "libertad, libertad" cuando descubrieron que el alcalde había excluído [sic] el español de la protesta (CORPES XXI, El hilo, blog de La Vanguardia [Esp.], 2005).

$b$. Los vecinos de Getxo, concentrados en contra del atentado, gritaron "libertad, libertad" cuando descubrieron que el alcalde había excluido el español de la protesta.

Debemos tener en cuenta que el criterio clasificador que estamos empleando es la categoría funcional del sintagma que conforma la oración de relativo, por lo que no sólo son relativas adjetivas las oraciones de (42-43), sino también aquellas introducidas por los relativos donde, cuando o como (44-46). Estas unidades pueden introducir oraciones que modifican a un sustantivo, por lo que su función sintáctica será la de adyacente nominal y, en consecuencia, su categoría sintáctica, la adjetiva, tal y como demuestra su conmutación por palabras de este tipo (44-46b):

(44) a. En los prados donde antaño pacían lustrosas reses campa ahora el cardo inhóspito (CORPES XXI, Mi viajera. Ciervos errantes y tigres invisibles [Esp.], 2001).

$b$. En los prados pacederos campa ahora el cardo inhóspito.

(45) a. El día cuando llegamos decidimos ir a la parte oeste de la isla (CORPES XXI, El verano interminable [Esp.], 2007).

$b$. El día siguiente decidimos ir a la parte oeste de la isla.

(46) a. Historiadores y antropólogos han empezado a tener mayor conciencia de la manera como sus etnografías e historias han sido moldeadas a través de los artificios retóricos y literarios (CORPES XXI, Espéculo [Esp.], 2002).

$b$. Historiadores y antropólogos han empezado a tener mayor conciencia de la manera retórica y literaria.

Puesto que estas oraciones equivalen categorialmente a adjetivos, es posible aplicar en ellas la clasificación semántica propia de estas unidades que permite diferenciar entre adje- 
tivos especificativos y explicativos (J.A. Martínez 1989; Iglesias Bango 2003). Por tanto, dentro de las relativas adjetivas es admisible diferenciar dos subtipos de oraciones a partir de su función semántica: relativas adjetivas especificativas (42; 44-46) y relativas adjetivas explicativas (43). No obstante, y a diferencia de las clasificaciones bipartitas tradicionales, consideramos que no se debe identificar necesariamente el concepto de especificativa con el de restrictiva y, por ende, tampoco el de explicativa con el de no restrictiva. Así, apoyamos la propuesta de RAE y ASALE (2009) al considerar que las relativas adjetivas especificativas son aquellas que ayudan a identificar el referente del antecedente, por lo que tal entidad no puede estar definida previa mención de la oración de relativo. Ese proceso de identificación puede realizarse por medio de una restricción de la clase designativa del antecedente (42; 44-46); pero también podría llevarse a cabo por otros medios. Por ejemplo, una relativa adjetiva especificativa puede apuntar simplemente un rasgo del referente que permite identificarlo sin necesidad de diferenciar más de un grupo de entidades dentro de su universo del discurso (23-25).

Las relativas adjetivas explicativas, en cambio, son aquellas que predican cierta información sobre un antecedente ya identificado, por lo que no son necesarias para reconocer el referente. Es por ello por lo que su elisión no altera la referencia del antecedente nominal al que modifican $(47 b)$ :

(47) a. DiCaprio, que pasa unos días en Ibiza, comenzará en breve el rodaje del nuevo trabajo de Christopher Nolan (CORPES XXI, El País [Esp.], 2009).

b. DiCaprio comenzará en breve el rodaje del nuevo trabajo de Christopher Nolan.

No obstante, no debemos confundir los conceptos de antecedente identificado y antecedente determinado, específico o concreto. Así, en un enunciado como (47), el antecedente de la relativa adjetiva explicativa, además de estar identificado, hace referencia a una persona concreta y específica: el actor Leonardo DiCaprio. En (48), sin embargo, el antecedente está identificado previa mención de la oración relativa; pero lo que ahora se identifica no son unos reptiles específicos de la realidad, sino todos aquellos animales que caben bajo esta denominación, es decir, su clase designativa: 
(48) Los reptiles, que incluyen lagartijas y lagartos, tortugas, culebras y cocodrilos, entre otros, suman algo menos de 7.000 especies (CREA, Vida. La naturaleza en peligro [Esp.], 2001).

2. Relativas sustantivas: son aquellas que equivalen categorialmente a sustantivos, de tal forma que pueden sustituirse por palabras de esta categoría gramatical o por pronombres (49-51b). En consecuencia, estas oraciones pueden desempeñar las funciones sintácticas propias de un sintagma nominal como sujeto, implemento, etcétera:

(49) $a$. El que recibe la llamada piensa también inmediatamente en lo peor (CORPES XXI, El abrecartas [Esp.], 2006).

b. Él piensa también inmediatamente en lo peor.

(50) a. Del total de la IDE mundial, son los países desarrollados los que han recibido una mayor proporción (CORPES XXI, América Latina en la encrucijada de la inserción internacional [Esp.], 2007).

b. Del total de la IDE mundial, los países desarrollados son ésos.

(51) a. Los niños mayores, los que habían conseguido eludir la expulsión y habían pasado a formar parte de la élite de los ladrones fogueados, no vivían en chabolas (CORPES XXI, Gálvez en la frontera [Esp.], 2001).

$b$. Los niños mayores, ellos, no vivían en chabolas.

Las relativas sustantivas pueden aparecer en construcciones apositivas, como (51); sin embargo, también es frecuente su uso en otro tipo de construcciones, como estructuras ecuacionales (50) o simplemente como funtivos que ejercen una determinada función sintáctica en estructuras no focalizadas (49). Es por ello por lo que consideramos que la clasificación de las oraciones relativas como "apositivas vs. no apositivas" no es algo intrínseco a la propia oración de relativo, sino que depende del contexto o construcción sintáctica en la que aparezca. A este respecto, lo primordial sería identificar el tipo de oración relativa en función de su categoría funcional y, sólo a posteriori, clasificar la construcción en la que aparece como apositiva o no apositiva. Ésta es, probablemente, la principal diferencia entre nuestra propuesta y las establecidas por J.A. Martínez (1989) e Iglesias Bango (2003). 
Por su parte, las relativas libres encabezadas por donde, cuando o como también constituyen relativas sustantivas por varias razones. En primer lugar, aunque las oraciones introducidas por dichas unidades funcionan generalmente como aditamentos, ésta es una función que también puede desempeñar un sintagma nominal -por ejemplo, (11). En segundo lugar, las oraciones con donde, cuando o como y sin un antecedente expreso admiten la sustitución por un sintagma nominal $(52-54 b)^{12}$ :

(52) a. Mandaré un coche a recogerles donde estén alojados (CORPES XXI, En tiempo de prodigios [Esp.], 2006).

$b$. Mandaré un coche a recogerles a ese lugar.

(53) a. Observar las barcas cuando descansan en el puerto (CORPES XXI, Pasiones romanas [Esp.], 2005).

b. Observar las barcas aquel día.

(54) a. Recomiendo proceder como indica a continuación para aislarlas (CORPES XXI, Tecnología para un progreso sostenible [Esp.], 2007).

b. Recomiendo proceder de esta manera.

Por último, las relativas libres introducidas por donde, cuando y como también pueden aparecer en estructuras ecuacionales (55), formadas por dos segmentos, una unidad focalizada y una oración de relativo, entre los que se establece una relación de atribución por medio del verbo ser. Tal y como argumentan Alarcos (1982 [1970]) y Gutiérrez Ordóñez (1986), dicha relación de atribución solamente se puede manifestar si entre ambos segmentos hay un paralelismo semántico y funcional: así, "si un segmento es sustantivo, el otro tendrá también carácter nominal" (Gutiérrez Ordóñez 1986, p. 57). En los ejemplos de (55), las unidades focalizadas, pese a estar precedidas por una preposición ${ }^{13}$, son sintagmas nominales -el mar,

12 Es cierto que en (52) y (54) el sintagma nominal aparece con una preposición. Sin embargo, desde las filas funcionalistas, se defiende que tal unidad no constituye más que un índice funcional que señala aquella función sintáctica que introduce. Véase Gutiérrez Ordóñez 1997.

${ }^{13}$ De hecho, es frecuente la ausencia de preposición en las unidades focalizadas de las estructuras ecuacionales: el mar es donde mejor se ve esa raya que se aleja. No obstante, Gutiérrez Ordóñez (1986) señala que, aunque posibles, estas estructuras sin preposición son anómalas. 
esa época, este modo-, por lo que las oraciones relativas introducidas por donde, cuando y como deben ostentar, igualmente, esta categoría funcional:

(55) a. En el mar es donde mejor se ve esa raya que se aleja (CORPES XXI, Cuadros de amor y humor, al fresco [Esp.], 2001).

$b$. En esa época fue cuando empezaron los problemas de los deportistas para salir de Cuba (CORPES XXI, $A B C$ [Esp.], 2006).

c. De este modo es como el montador va hilando y obteniendo esa continuidad y ritmo tan deseados entre planos (CORPES XXI, Montaje. Una profesión de cine [Esp.], 2002).

Estos tres aspectos, por tanto, parecen indicar que las relativas libres introducidas por donde, cuando o como pertenecen a la categoría nominal, lo que justifica su consideración como relativas sustantivas, y no como adverbiales (J.A. Martínez 1989; Brucart 1999). Ello permite, además, mantener un análisis común para todas las relativas libres: tanto aquellas introducidas por unidades que tradicionalmente han sido catalogadas como "pronombres relativos" -por ejemplo, quien- como aquellas encabezadas por los tradicionales "adverbios relativos" -donde, cuando, como(RAE y ASALE 2009).

3. Relativas adverbiales: son aquellas oraciones que equivalen categorialmente a sintagmas adverbiales, por lo que desempeñan funciones sintácticas propias de esta categoría, como adyacente de un adjetivo o de un adverbio (56):

(56) a. Temo acercarme a los demás sólo para comprobar lo lejos que estoy (CORPES XXI, Defensa personal [Esp.], 2003).

b. Luego volvió a sonreír y abrió los brazos en cruz como quien quiere enseñar lo bien que se encuentra (CORPES XXI, Canto rodado [Esp.], 2007).

Es cierto que el sintagma compuesto por el antecedente y la oración relativa se adscribe a la categoría nominal (57b), pero ello no debe llevarnos a considerar que la propia oración de relativo también pertenece a tal categoría. En primer lugar, si así fuera, no sólo las relativas adverbiales deberían considerarse como sustantivas, sino también las relativas adjetivas, pues la suma del antecedente y la oración de relativo conforma asimismo un sintagma nominal en estos casos (58b). Debemos, por tanto, tener en cuenta que aquello que estamos categorizando 
no es la unidad compuesta por el antecedente y la oración de relativo, sino únicamente el segundo de estos segmentos.

(57) a. Temo acercarme a los demás sólo para comprobar [lo lejos que estoy].

b. Temo acercarme a los demás sólo para comprobar [eso].

(58) a. [Los vecinos que se concentraron] gritaron "libertad".

b. [Ellos] gritaron "libertad".

En segundo lugar, sería posible argumentar que el adjetivo o adverbio que funciona como antecedente en las relativas adverbiales está sustantivado por medio del artículo lo y que, por ende, la oración de relativo pertenecería a la categoría adjetiva. No obstante, estimamos que este análisis no es correcto, pues el artículo lo no sustantiva únicamente al adjetivo o adverbio antecedente, sino al sintagma compuesto por dicha unidad y la oración de relativo. Prueba de ello es el hecho de que si el artículo sustantivase exclusivamente al antecedente, debería concordar en género y número con este segmento -al menos cuando fuese un adjetivo (59a-b)-, tal y como ocurre en las verdaderas sustantivaciones de adjetivos $(59 b-c)$.

(59) a. Me sorprendió lo listos que son.

$b$. Me sorprendió lo listas que son.

c. Los listos me sorprendieron.

d. Las listas me sorprendieron.

Asimismo, en ciertos contextos, el artículo que precede al antecedente adjetivo o adverbial puede ser elidido (60), por lo que en estos casos no sería posible la sustantivación de tal antecedente y, por ello, tampoco el análisis de la oración relativa como adjetiva (J.A. Martínez 1989).

(60) a. Por listos que sean no entenderán tu posición.

$b$. Por lejos que viajen siempre regresarán.

Así pues, consideramos que las oraciones encabezadas por un relativo en (56), (59a-b) y (60) modifican exclusivamente al adverbio o adjetivo antecedente, por lo que su categoría sintáctica sería la propia de los sintagmas adverbiales. Atendiendo, entonces, al criterio de la categoría funcional, estas estructuras constituirían un tercer tipo de oración de relativo: las relativas 
adverbiales. Pese a que el concepto de relativa adverbial no sea novedoso en sí mismo, las unidades que conforman esta clase sí difieren respecto de clasificaciones previas, en las que se suelen analizar como adverbiales aquellas estructuras introducidas por los adverbios relativos (Gili Gaya 1961; RAE 1973; Marcos Marín 1980; Alarcos 1994).

\section{Conclusión}

El objetivo del presente artículo era introducir una nueva propuesta de clasificación de las oraciones de relativo. Es cierto que son múltiples las clasificaciones que se han realizado de este tipo de oraciones a lo largo de la historia de la gramática hispánica y que éstas, además, atienden a criterios de diversa índole: semánticos, sintácticos o una combinación de ambos. Sin embargo, la mayoría de estas propuestas presenta ciertas limitaciones que pasan, en un gran número de casos, por no incluir la gran variedad de estructuras que pueden introducirse por un relativo. Así, las principales obras gramaticales del español suelen incluir en sus clasificaciones de las oraciones de relativo aquellas estructuras prototípicas que funcionan como sintagmas adjetivos; pero dejan de lado un gran número de construcciones que, pese a no ser adjetivas, cumplen igualmente los requisitos de una oración relativa (De Vries 2002). Tal y como apuntamos líneas arriba, probablemente esta exclusión se deba al gran peso que la tipología clásica ha tenido, y sigue teniendo, en la tradición gramatical, pues muchos de los estudiosos, aunque no incluyan esas relativas no prototípicas explícitamente en sus clasificaciones, sí las analizan como cuestión aparte (Bello 1978 [1847]; Gili Gaya 1961; RAE 1973; Alcina y Blecua 1975; Alarcos 1994; Porto Dapena 1997; Brucart 1999; RAE y ASALE 2009).

Teniendo en cuenta estos aspectos, proponemos una tipología de las oraciones de relativo (cf. infra, Diagrama 1) en la que el criterio clasificador sea la categoría funcional del sintagma constituido por la propia oración relativa. Ello permite diferenciar y, por ende, catalogar no sólo las relativas que funcionan como sintagmas adjetivos (relativas adjetivas), sino también aquellas que funcionan como sintagmas nominales (relativas sustantivas) o adverbiales (relativas adverbiales), independientemente del tipo de construcción sintáctica en la 
que aparezcan: apositiva o no apositiva, focalizada o no focalizada.

A esta primera distinción, sería posible añadir una segunda, de tal forma que la clasificación de los adjetivos en especificativos vs. explicativos también pudiese aplicarse a aquellas relativas que pertenezcan a esta categoría funcional. Así, las relativas adjetivas se subdividirían en especificativas o explicativas a partir de los rasgos referenciales del antecedente y de la función semántica que, en consecuencia, desempeña la oración relativa: mientras que las adjetivas especificativas permiten identificar el referente de un antecedente no conocido, las adjetivas explicativas añaden cierta información sobre un referente ya identificado (Aletá Alcubierre 1990; RAE-ASALE 2009). Estas definiciones evitan, por consiguiente, establecer un paralelismo, muchas veces erróneo, entre especificativas y restrictivas, así como entre explicativas y no restrictivas.

\section{Diagrama 1}

Propuesta de clasificación de las oraciones de relativo

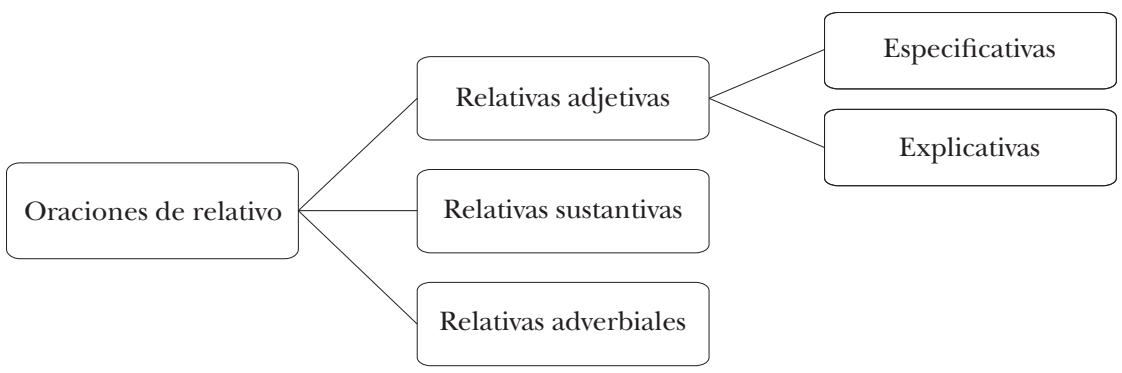

REFERENCIAS

Fuentes documentales

CORPES XXI = Real Academia Española: Banco de datos (CORPES XXI) [en línea]. Corpus del español del siglo XXI (CORPES), http://web.frl.es/ CORPES/view/inicioExterno.view [consultado el 3 de agosto de 2019]. CREA = Real Academia Española: Banco de datos (CREA) [en línea]. Corpus de referencia del español actual, http://web.frl.es/CREA/view/inicioExterno.view [consultado el 3 de agosto de 2019]. 


\section{Referencias bibliográficas}

Alarcos Llorach, Emilio 1982 [1970]. Estudios de gramática funcional del español, $3^{\text {a }}$ ed., Gredos, Madrid.

Alarcos Llorach, Emilio 1994. Gramática de la lengua española, Espasa, Madrid.

Alcina Franch, Juan y José Manuel Blecua 1975. Gramática española, Ariel, Barcelona.

Aletá Alcubierre, EnriQue 1990. Estudios sobre las oraciones de relativo, Universidad de Zaragoza, Zaragoza.

Bello, Andrés 1978 [1847]. Gramática de la lengua castellana, Edaf, Madrid.

BRUCART, José MARÍA 1999. "La estructura del sintagma nominal: las oraciones de relativo", en Gramática descriptiva de la lengua española. Coords. Ignacio Bosque y Violeta Demonte, Espasa-Calpe, Madrid, t. 1, pp. 395522.

Coseriu, Eugene 1977. El hombre y su lenguaje, Gredos, Madrid.

De Vries, Mark 2002. The syntax of relativization, tesis, Universiteit van Amsterdam, en http://www.let.rug.nl/dvries/pdf/proefschrift-mdevries.pdf [consultado el 22 de junio de 2019].

D’Introno, Francesco 1979. Sintaxis transformacional del español, Cátedra, Madrid.

D’Introno, Francesco 2001. Sintaxis generativa del español: evolución y análisis, Cátedra, Madrid.

Donzé, Roland 1970. La gramática general y razonada de Port-Royal: contribución a la historia de las ideas gramaticales en Francia, Eudeba, Buenos Aires.

Downing, Bruce 1978. "Some universals of relative clause structure", en Universals of human language. T. 4: Syntax. Ed. Joseph H. Greenberg, Stanford University Press, Stanford, pp. 375-418.

Gili Gaya, Samuel 1961. Curso superior de sintaxis española, Vox, Barcelona.

Grosu, Alexander \& Fred Landmann 1998. "Strange relatives of the third kind”, Natural Language Semantics, 6, pp. 125-170.

GutiérRez OrdóÑez, SAlvador 1986. Variaciones sobre la atribución, Universidad de León, León. (Contextos, 5 ).

Gutiérrez Ordóñez, Salvador 1997. Principios de sintaxis funcional, Arco/ Libros, Madrid.

Iglesias BAngo, MANuel 2003. "Algunas construcciones incidentales con el relativo /como/ en español", Contextos, pp. 1-113, en http://www.revistacontextos.es/econtextos/02_Manuel_Iglesias.pdf [consultado el 18 de julio de 2018].

Lehmann, Christian 1984. Der Relativsatz, Gunter Narr Verlag, Tübingen.

Luján, Marta 1980. Sintaxis y semántica del adjetivo, Cátedra, Madrid.

Marcos Marín, Francisco 1980. Curso de gramática española, Cincel, Madrid.

Marcos Marín, Francisco, F. Javier Satorre Grau y María Luisa Viejo Sánchez 1998. Gramática española, Síntesis, Madrid.

Martínez, José Antonio 1989. El pronombre. T. 2: Numerales, indefinidos y relativos, Arco/Libros, Madrid.

Martínez, José Antonio 1994. Cuestiones marginadas de gramática española, Istmo, Madrid. 
Matte Bon, Francisco 1995 [1992]. Gramática comunicativa del español, Difusión, Madrid.

Moreno Cabrera, Juan Carlos 1991. Curso universitario de lingüistica general. T. 1: Teoría de la gramática y sintaxis general, Síntesis, Madrid.

OJea López, ANa Isabel 1992. Los sintagmas relativos en inglés y español, Universidad de Oviedo, Oviedo.

Porto Dapena, José Álvaro 1997. Oraciones de relativo, Arco/Libros, Madrid.

RAE $=$ Real Academia Española 1973. Esbozo de una nueva gramática de la lengua española, Espasa-Calpe, Madrid.

RAE y ASALE = Real Academia Española y Asociación de Academias de la Lengua Española 2009. Nueva gramática de la lengua española, Espasa, Madrid.

Roca-Pons, José 1960. Introducción a la gramática, Teide, Barcelona.

Suñer Gratacós, Avelina 1999. "La aposición y otras relaciones de predicación en el sintagma nominal", en Gramática descriptiva de la lengua española. Coords. I. Bosque y V. Demonte, Espasa-Calpe, Madrid, t. 1, pp. 523-564. 